\title{
Are The Medications That We Are Prescribing To Our Patients Harming Them?
}

\author{
Huang Wei Ling \\ Infectious Diseases, General Practice, Nutrition, Acupuncture and Pain Management. Medical Acupuncture \\ and Pain Management Clinic, Franca, São Paulo, Brazil
}

*Corresponding Author: Huang Wei Ling, Rua Homero Pacheco Alves, 1929, Franca, São Paulo, Brazil.14400-010, Email: weilingmg@gmail.com

\section{Editorial}

Since 1913, when the commandments of the Flexner report were implemented, several medical schools had to adapt to the new models and others had to be closed (many of which treated patients with models linked more to the energy aspect such as homeopathy and oriental medicines). [1]

This affected all institutions in the Americas, Europe and Asia, but some negative points can be observed from this implementation that completed its centenary in 2013. [1]

In the book written by Capra (1975) entitled The Tao of Physics, the author describes the intricate complex that exists between the two medicines of the West (influenced by Galen and after by the Flexner report) and traditional Chinese medicine (that existed for more than 5,000 years). According to Capra, everything that exists in the universe is formed of energy including human beings. [2]

The author, in her publications demonstrating the different aspects of the treatment of a disease, emphasizes the need to treat the patient, with their energy imbalances and not only the symptoms such as in the article written by the author (2020) entitled Why patients with knee pain still have symptoms despite the use of antiinflammatory medications? In this article, the author is saying that the knee pain symptoms are only manifestations of internal energy imbalances because the knee is an organ commanded by the Kidney energy (second chakra) and also by the Liver and Gall-bladder meridian (first chakra). In this article, the author explained why patients do not improve their knee pain when they are simply given medication to relieve the knee pain (with the use of anti-inflammatory drugs) because they are not addressing the cause, which is at the energy level, which today we are not teaching to the new doctors in the medical schools, due to the influences of Flexner report. [1, 3]

In all her articles, she demonstrates that the treatment of the root of the problem shown by the metaphor of the tree, manages to treat several symptoms of several specialties at the same time, as she demonstrated this theory in the Acupuncture Research Conference that was held in Harvard Medical School in 2015 in a presentation entitled Acupuncture Viewed Holistically Can Treat All the Patients Conditions at The Same Time. [4]

With regard to orthopedics, bone, tendon, muscles have a lot of relationship between the internal organs in Chinese medicine, which Western medicine is not aware of, as their model follows the Galen's theory, which sees the patient divided into systems that work independently without connection with the other organs. [5, 6]

In the author's daily practice, demonstrates through some studies that, patients with tendon problems can only be manifestations of problems in internal organs, more specifically related to a disequilibrium in the energy of the Gallbladder as she showed in the article written by her (2019) Shoulder and Elbow Tendinitis as Initial Manifestation of Autoimmune Hepatitis. [7]

This is just an example that the model of medicine that we are using today, treating only the symptom and ignoring the real factors that are generating the diseases, is no longer enough to treat patients who need healing, as she wrote (2021) in the article Is the Population in the 
World the Same as in the Past? And Is the Medication Used in Intubation of Patients with COVID-19 Affecting The Outcome of the Patient's Treatment? [8,9]

What worried the author is that in a study carried out by her (2021) between 2015 and 2020, published in the article Energy Alterations and Chakras' Energy Deficiencies and Propensity to SARS-CoV-2 Infection, the same demonstration that more than 90 percent of patients are without energy in their internal organs, including the organs that are responsible for maintaining the health of bones, tendons, muscles. The majority of the doctors are unaware of this new information of the energy situation that our population is currently experiencing, caused by the modernization of communication systems worldwide through $5 \mathrm{G}$ technology, as the author (2021) wrote in the article Is the Population in the World the Same as in the Past? $[8,10]$

Other ways to decrease vital energy are in the placement of pins, plates, screws, very common in the treatment of orthopedic problems in addition to the prostheses performed in all orthopedic surgeries that even the highest echelons of the largest universities in the world are unaware that the placement of these materials is causing a reduction in this vital energy, as the author (2019) presented in many webinars such as in the Webinar on Dental Health on May $29^{\text {th }} 2021$ and published in the article entitled Can Metallic Surgical Implants Influence the Body's Health?[11]

This energy is the major importance for survival and to prevent diseases such as diabetes, myocardial infarction, stroke, cancer, infection with COVID- 19 among many other diseases. [10- 13]

Therefore, through this editorial, the author is warning all the physicians to expand their vision regarding the view they have about their patient because with these changes in the energy pattern of the human being, if the doctor does not pay attention to the changes (that is not visible by the naked eyes) we can cause more harm than good and also cause great side effects due to the type of medication that we are currently prescribing, very well explained by the Arndt Shultz law created in 1888. In this law, the two German researchers said that the use of highly concentrated drugs cause a reduction in vital energy, which could lead to death. Therefore, we need to understand that human beings are changing their energy pattern and more highly diluted drugs will need to be prescribed, for their human to improve their symptoms and their energy and not get worse, if you we continue to use highly concentrated medications, demonstrated by this law. [14]

New reforms in the curricular structures of medical schools in the whole world need to be quickly reevaluated because the doctors that the majority of these medical schools are preparing are not attending to the type of patient they have today as demonstrated in the article Is the Population in the World the Same as in the Past? [8]

According to Hippocrates, we must consider the older medicines before considering the medicine we are doing today and we need to integrate the two medicines today to understand in a deepest way, how the human body works. Both are explaining the human being in two ways to thinking but one, in one level and the other in another level but both belongs to the same person that is our patient. [15]

\section{REFERENCES}

[1] Flexner, A., Updike, D. B., Pritchett, H. S., Carnegie Foundation for the Advancement of Teaching., \& Merrymount Press,. (1910). Medical education in the United States and Canada: A report to the Carnegie foundation for the advancement of teaching.

[2] Capra, Fritjof. The Tao Of Physics: an Exploration of the Parallels between Modern Physics and Eastern Mysticism. Berkeley : [New York] :Shambhala ; distributed in the U.S. by Random House, 1975.

[3] Huang WL. "Why patients with knee pain still have symptoms despite the use of antiinflammatory medications". Journal of Clinical Anesthesiology: Open Access 2.2 (2020): 21-7.

[4] Huang WL. "The Importance of Correcting Energy Imbalances and Chakras Energy Deficiencies in the Treatment of Patients with Glaucoma". Journal of Ophthalmology and Clinical Research 2.2 (2019): 1-9.

[5] Nutton V. The fatal embrace: Galen and the history of ancient medicine.Sci Context. 2005 Mar;18(1):111-21. doi: 10.1017/s0269889705000384.

[6] Huang WL. "Why do Patients Still Catch Hospital Infections Despite the Practice of Infection Prevention and Control Programs?" Acta Scientific Microbiology 1.4 (2018): 34-43

[7] Huang WL. Shoulder and Elbow Tendinitis as Initial Manifestation of Autoimmune Hepatitis. ARC Journal of Orthopedics Volume 4, Issue 2, 2019, PP 19-26 ISSN 2456-0588 DOI: http://dx.doi.org/10.20431/2456-0588.0402004. 
[8] Huang WL. "Is the Population in the World the Same as in the Past?". Acta Scientific Clinical Case Reports 2.6 (2021).

[9] Huang Wei Ling. Is the Medication used in Intubation of Patients with Covid-19 Affecting the Outcome of the Patient's Treatment?. Archives of Anesthesiology. 2021; 4(1): 01-03

[10] Huang Wei Ling. "Energy Alterations and Chakras' Energy Deficiencies and Propensity to SARS-CoV-2 Infection". Acta Scientific Microbiology 4.4 (2021): 167-196.

[11] Huang Wei Ling. "Can Biomaterial Surgical Implants Influence the Body's Health?". Acta Scientific Medical Sciences 3.9 (2019): 62-71.

[12] Huang WL. "Why Are Diabetic Patients Still Having Hyperglycemia despite Diet
Regulation, Antiglycemic Medication and Insulin?" International Journal of Diabetes and Metabolic Disorder 4.2 (2019): 1-14.

[13] Huang WL. "The Importance of Correcting Energy Imbalances in the Prevention and Treatment of Câncer". Advances in Cancer Research and Clinical Imaging 3.1 (2020): 110.

[14] LEESER O. Support of homeopathy by the Arndt-Schulz law. National Center for Biotechnology Information. 1953/ Jul 31.

[15] Yapijakis C. "Hippocrates of Kos, the father of clinical medicine, and asclepiades of Bithynia, the father of molecular medicine". In Vivo (Brooklyn) 2.4 (2009): 507-514.

Citation: Huang Wei Ling. "Are The Medications That We Are Prescribing To Our Patients Harming Them?”. 2021; 6(1):11-13. DOI: https://doi.org/10.20431/2456-0588.0601003.

Copyright: () 2021 Authors. This is an open-access article distributed under the terms of the Creative Commons Attribution License, which permits unrestricted use, distribution, and reproduction in any medium, provided the original author and source are credited. 